\title{
PENGGUNAAN PROGRAM CPCE (CORAL POINT COUNT WITH EXCEL EXTENSIONS) UNTUK MENGETAHUI KONDISI TERUMBU KARANG DI PERAIRAN SEKITAR PULAU BATAM
}

\author{
Anindyta Fitria Ramadhani ${ }^{a}$, Oktiyas Muzaky Luthfi ${ }^{a^{*}}$, Rizkie Satriya Utama ${ }^{b}$ \\ ${ }^{a}$ Program Studi Ilmu Kelautan, Fakultas Perikanan dan Ilmu Kelautan Universitas Brawijaya Malang, \\ Jl. Veteran Malang, Jawa Timur 65145, Indonesia \\ ${ }^{\text {b} P u s a t ~ P e n e l i t i a n ~ O s e a n o g r a f i ~-~ L I P I, ~ J l . ~ P a s i r ~ P u t i h ~ I, ~ A n c o l ~ T i m u r, ~ J a k a r t a ~ 14430, ~ I n d o n e s i a ~}$ \\ *Koresponden penulis : omuzakyl@ub.ac.id
}

\begin{abstract}
Abstrak
Ekosistem terumbu karang yang sehat akan dijadikan sebagai tempat pemijahan serta ladang mencari makan berbagai biota laut. Dengan tingginya produktivitas primer dan keanekaragaman, ekosistem terumbu karang akan menjadi ekosistem yang mempunyai banyak potensi yang bermanfaat. Pulau Abang dan Pulau Abang Besar,Batam, merupakan salah satu lokasi dengan ekosistem terumbu karang yang baik. Sayangnya, ekosistem tersebut telah banyak terjamah oleh kehadiran wisatawan yang melakukan wisata bahari. Maka dari itu, pengamatan diperlukan untuk mengetahui kondisi terumbu karang yang berada di Pulau Abang dan Pulau Abang Besar. CPCe atau Coral Point Count with Excel Extensions adalah salah satu perangkat lunak yang membantu untuk mengidentifikasi dan mengetahui kondisi terumbu karang di suatu wilayah. Pengolahan data pada program CPCe ini akan mengasilkan data berupa file Excel yang menunjukkan hasil analisa identifikasi. Berdasarkan pengolahan data menggunakan program CPCe, didapatkan hasil persentase tutupan karang pada ke-enam stasiun bervariasi $(32.67$ - 51.33\%) dari kategori rusak hingga baik. Pada stasiun 1 atau BTMC01 mempunyai tutupan karang tertinggi yaitu sebesar $51.33 \%$ dan yang terendah terdapat pada stasiun 2 atau BTMC02 sebesar 32.67\%. Kondisi terumbu karang dengan kategori baik hanya terdapat pada BTMC01, sisanya memiliki kondisi terumbu karang dengan kategori sedang. Nilai persentase tutupan karang yang didapatkan merupakan gabungan antara spesies kelompok karang Acropora dan NonAcropora. Baik atau buruknya tutupan karang pada suatu wilayah sangat dipengaruhi oleh kegiatan antropogenik.
\end{abstract}

Kata Kunci: Coral Point Count with Excel Extensions (CPCe), Kondisi, Pulau Abang, Pulau Abang Besar, Terumbu Karang

\begin{abstract}
A healthy coral reef ecosystem will be used as a place for spawning and foraging for various marine biota. With high primary productivity and diversity, coral reef ecosystems will become ecosystem that has a lot of useful potential. Abang Island and Abang Besar Island, Batam, are two of the locations with a good coral reef ecosystem. Unfortunately, these ecosystems have been disturbed by marine tourism activities. Therefore, observations are needed to determine the condition of coral reefs in Abang and Abang Besar Islands. Coral Point Count with Excel Extensions (CPCe) is a software that helps to identify and know the condition of coral reefs in an area. Data processing in this CPCe program will generate data in the form of Excel files that show the results of identification analysis. Based on data processing using the CPCe program, the results of the percentage of coral cover at the six stations varied (32.67-51.33\%) from the bad to good categories. At Station 1 or BTMCO1, the highest coral cover is $51.33 \%$ and the lowest is at Station 2 or BTMC02 at 32.67\%. The condition of coral reefs with good categories is only found in BTMC01, the rest has the condition of coral reefs in the medium category. The percentage of coral cover obtained is a combination of Acropora and Non-Acropora coral group species. Good or bad coral cover in an area is strongly influenced by anthropogenic activities.
\end{abstract}

Keywords: Coral Point Count with Excel Extensions (CPCe), Condition, Abang Island, Abang Besar Island, Coral Reef 


\section{PENDAHULUAN}

Monitoring kesehatan terumbu karang didefinisikan sebagai kegiatan pengumpulan data dan informasi bio-ekologi kelompok biota yang ditetapkan sebagai indikator kesehatan terumbu karang serta data perubahan sosial ekonomi masyarakat pesisir sebagi penerima dampak dari pemanfaatan dan pengelolalaan sumberdaya serta upaya konservasi dan rehabilitasi ekosistem terumbu karang. Monitoring yang baik didasarkan pada sebuah keteraturan pengulangan dan dilakukan dalam seri waktu dan penambahan luas area yang terwakili. Perubahan dalam seri waktu dan rentang spasial yang diukur selama monitoring akan menyediakan data dan informasi penting terhadap perubahan populasi biota indikator di ekosistem pesisir dan pulau-pulau kecil sebagai tolak ukur keberhasilan intervensi sebuah program pengelolaan dan perlindungan sumberdaya, termasuk terumbu karang dan ekosistem terkait lainnya [1].

Indikator kesehatan terumbu karang terdiri dari tutupan karang hidup dan bentik terumbu lainnya, ikan karang yang terdiri ikan corallivor, herbivor dan target, serta mega benthos dan didukung oleh kesehatan ekosistem lainnya seperti padang lamun dan mangrove. Indikator kesehatan terumbu karang dapat dianalisa menggunakan software CPCe (Coral Point Count with Excel extension) untuk memperoleh nilai persentase tutupan karang [2].

Ekosistem Terumbu karang yang sehat memiliki daya tarik bagi para wisatawan lokal maupun mancanegara. Pulau Abang dan Pulau Abang Besar merupakan salah satu destinasi wisata keindahan terumbu karang di Kota Batam. Masyarakat sekitar pulau tersebut mempromosikan keindahan terumbu karang di Pulau Abang dan Pulau Abang Besar melalui wisata bahari yang dibuka pada tahun 2011. Hingga saat ini, Pulau Abang dan Pulau Abang Besar telah menjadi ikon wisata keindahan terumbu karang di Kota Batam. Kondisi tersebut yang melatar belakangi peneliti untuk melakukan penelitian agar mengetahui kondisi tutupan terumbu karang di beberapa spot wisata di pulau tersebut [3]. Tujuan dari penulisan jurnal ini adalah untuk mengukur kondisi terumbu karang yang ada di perairan sekitar Pulau Batam dengan menggunakan program CPCe. Hasil dari pengolahan data ini nantinya dapat dijadikan sebagai data monitoring tahunan dan data time series perkembangan kondisi terumbu karang di sekitar perairan Pulau Batam.

\section{BAHAN DAN METODE}

Penelitian ini dilakukan di perairan sekitar Pulau Batam, tepatnya di Pulau Abang dan Abang Besar. Terdapat 2 stasiun yang berada di Pulau Abang yaitu BTMC01 dan BTMC02. Sedangkan Pulau Abang Besar memliki 4 stasiun yaitu BTMC03, BTMC04, BTMC05, dan BTMC06 (Gambar 1). Kedua Pulau ini memiliki karakteristik yang berbeda, setiap stasiunnya juga berbeda baik dari segi posisi dan keadaan fisik (Tabel 2).



Gambar 1. Peta pengamatan di perairan Batam

Pengolahan data identifikasi karang dilakukan agar dapat mengetahui kondisi terumbu karang di Pulau Abang dan Pulau Abang Besar, Batam. Data identifikasi karang diperoleh dengan mengambil foto transek disetiap meternya menggunakan bingkai dengan ukuran $58 \mathrm{~cm} \times 44 \mathrm{~cm}$ dengan panjang line transek sepanjang 50 meter [4]. Foto - foto tersebut kemudian di pilah dan diidentifikasi menggunakan software CPCe 
(Coral Point Count with Excel Extensions). $\mathrm{CPCe}$ juga digunakan untuk menghitung persentase tutupan dari masing - masing kategori [5]. Dalam identifikasi karang, digunakan 30 titik yang acak dimana setiap substrat ataupun biota yang terkena titik akan dikategorikan dengan menggunakan pengkategorian sesuai Giyanto et al. (2014) [1]. Status kondisi terumbu karang ditentukan menggunakan tingkat tutupan karang hidup menurut Sukarno (1993) [6] (Tabel 1).
Tabel 1. Tingkat kondisi terumbu karang

Persen Cover $(\%)$

Kondisi Terumbu Karang

\begin{tabular}{cc}
\hline $0-24$ & Rusak berat \\
$25-49$ & Rusak \\
$50-74$ & Baik \\
$75-100$ & Sangat Baik
\end{tabular}

Tabel 2. Deskripsi, posisi, dan lokasi pengamatan

\begin{tabular}{|c|c|c|c|c|c|}
\hline No & Stasiun & Longitute & Latitude & Lokasi & Deskripsi \\
\hline 1 & BTMC01 & $104.2212^{\circ}$ & $0.5357^{\circ}$ & Pulau Abang & $\begin{array}{l}\text { Pantai berupa pecahan karang dan } \\
\text { berpasir, lereng karang landai } \\
\text { dengan kemiringan } 30^{\circ} \text {, perairan } \\
\text { jernih }\end{array}$ \\
\hline 2 & ВТМC02 & $104.2403^{\circ}$ & $0.5413^{\circ}$ & Pulau Abang & $\begin{array}{l}\text { Pantai berbatu, lereng karang landai } \\
\text { dengan kemiringan } 30^{\circ}-40^{\circ} \text {, } \\
\text { perairan sedikit keruh }\end{array}$ \\
\hline 3 & ВТМС03 & $104.1893^{\circ}$ & $0.5542^{\circ}$ & $\begin{array}{l}\text { Pulau Abang } \\
\text { Besar }\end{array}$ & $\begin{array}{l}\text { Pantai berpasir putih, lereng karang } \\
\text { landai dengan kemiringan } 60^{\circ} \text {, } \\
\text { perairan cukup keruh }\end{array}$ \\
\hline 4 & ВТМC04 & $104.1763^{\circ}$ & $0.5850^{\circ}$ & $\begin{array}{l}\text { Pulau Abang } \\
\text { Besar }\end{array}$ & $\begin{array}{l}\text { Pantai berupa pecahan karang dan } \\
\text { berpasir, lereng karang landai } \\
\text { dengan kemiringan } 45^{\circ} \text {, perairan } \\
\text { cukup keruh }\end{array}$ \\
\hline 5 & ВТMC05 & $104.2020^{\circ}$ & $0.6045^{\circ}$ & $\begin{array}{l}\text { Pulau Abang } \\
\text { Besar }\end{array}$ & $\begin{array}{l}\text { Rataan karang mencapai } 100 \mathrm{~m} \text {, } \\
\text { peraiaran keruh, jarak pandang } \\
\text { mencapai } 8-10 \mathrm{~m}\end{array}$ \\
\hline 6 & ВТМC06 & $104.2242^{\circ}$ & $0.5818^{\circ}$ & $\begin{array}{l}\text { Pulau Abang } \\
\text { Besar }\end{array}$ & $\begin{array}{l}\text { Pantai berbatu, lereng karang landai } \\
\text { dengan kemiringan } 40^{\circ} \text {, perairan } \\
\text { cukup keruh }\end{array}$ \\
\hline \multicolumn{4}{|c|}{ HASIL DAN PEMBAHASAN } & \multirow{2}{*}{\multicolumn{2}{|c|}{$\begin{array}{l}\text { kategori rusak. Nilai persentase tutupan } \\
\text { karang yang didapatkan merupakan gabungan } \\
\text { antara spesies kelompok karang Acropora dan } \\
\text { Non-Acropora. Baik atau buruknya tutupan } \\
\text { karang pada suatu wilayah sangat dipengaruhi } \\
\text { oleh kegiatan antropogenik. }\end{array}$}} \\
\hline \multicolumn{4}{|c|}{$\begin{array}{l}\text { Nilai persentase tutupan karang pada ke- } \\
\text { enam stasiun bervariasi }(32.67-51.33 \% \text { ) dari } \\
\text { kategori rusak hingga baik (Tabel 3). Pada }\end{array}$} & & \\
\hline
\end{tabular}
stasiun 1 atau BTMC01 mempunyai tutupan karang tertinggi yaitu sebesar $51.33 \%$ dan yang terendah terdapat pada stasiun 2 atau BTMC02 sebesar $32.67 \%$ (Gambar 2). kondisi terumbu karang dengan kategori baik hanya terdapat pada BTMC01, sisanya memiliki kondisi terumbu karang dengan

\section{BTMC01 (Stasiun 1)}

Berdasarkan gambar 3a, CM mendominasi perairan pada stasiun BTMC01 dengan nilai tutupan sebesar 20,07\%, sedangkan nilai tutupan terendah terdapat pada CMR dengan 
nilai $1,20 \%$. CE dan CS memiliki nilai tutupan yang hampir sama yaitu masing masing $13,47 \%$ dan $12,60 \%$. Mengapa CM mendominasi perairan di stasiun BTMC01, hal ini diduga karena bentuk pertumbuhan $\mathrm{CM}$ tahan dengan arus yang kuat, hal ini didukung dengan pernyataan Luthfi et al. (2018) [7] yaitu karang dengan bentuk pertumbuhan masif memiliki ketahanan terhadap arus, gelombang, sedimentasi yang tinggi serta kenaikan suhu. Genus yang mendominasi pada stasiun BTMC01 ini adalah Porites sp., Montipora sp., dan Pectinia sp.

\section{BTMC02 (Stasiun 2)}

Berdasarkan gambar 3b, CS mendominasi perairan pada stasiun BTMC02 dengan nilai tutupan sebesar $10 \%$, sedangkan nilai tutupan terendah terdapat pada ACT dengan nilai 7,47\%. CE dan CM memiliki nilai tutupan yang sama yaitu $4,73 \%$. Mengapa CS mendominasi perairan di stasiun BTMC01, hal ini diduga karena bentuk pertumbuhan CS tahan dengan gelombang dan sedimentasi yang tinggi. Stasiun ini berada di dekat pemukiman nelayan yang membangun rumahnya diatas permukaan air. Banyaknya aktivitas antropogenik membuat perairan disekitar stasiun BTMC02 sedikit keruh. Genus yang mendominasi pada stasiun BTMC02 ini adalah Porites sp., Fungia sp., dan Pavona sp.

\section{BTMC03 (Stasiun 3)}

Berdasarkan gambar 3c, CM mendominasi perairan pada stasiun BTMC03 dengan nilai tutupan sebesar 20,1\%, sedangkan nilai tutupan terendah terdapat pada CME dengan nilai $0,1 \%$. Mengapa $\mathrm{CM}$ mendominasi perairan di stasiun BTMC03, hal ini diduga karena bentuk pertumbuhan $\mathrm{CM}$ tahan dengan arus yang kuat dan didukung dengan pernyataan Luthfi et al. (2018) [7] yaitu karang dengan bentuk pertumbuhan masif memiliki ketahanan terhadap arus, gelombang, sedimentasi yang tinggi serta kenaikan suhu. Stasiun ini memiliki perairan yang cukup keruh karena substrat yang mendominasi berupa pasir lumpur. Genus yang mendominasi pada stasiun ini adalah Porites sp., dan Montipora sp.

\section{BTMC04(Stasiun 4)}

Berdasarkan gambar 3d, CE mendominasi perairan pada stasiun BTMC04 dengan nilai tutupan sebesar $14,20 \%$, sedangkan nilai tutupan terendah terdapat pada CMR dengan nilai $0,27 \%$. Jenis yang paling banyak ditemukan setelah CE adalah CS yang memiliki nilai tutupan sebesar $10,20 \%$. Mengapa CE mendominasi perairan di stasiun BTMC04, hal ini diduga karena bentuk pertumbuhan CE dapat tumbuh dengan baik di habitat yang cukup dalam dibanding jenis lainnya dan didukung dengan pernyataan Harahap (2004) [8], yaitu tekanan yang diterima oleh biota di kolom perairan akan semakin besar jika perairan semakin dalam. Sehingga CE dengan bentuknya yang mengerak atau merayap mengikuti bentuk substrat dapat tumbuh dengan baik. Genus yang mendominasi pada stasiun BTMC04 ini adalah Porites sp., dan Pavona sp.

\section{BTMC05 (Stasiun 5)}

Berdasarkan gambar 3e, CM mendominasi perairan pada stasiun BTMC05 dengan nilai tutupan sebesar $9,2 \%$, sedangkan nilai tutupan terendah terdapat pada ACT dan $\mathrm{CB}$ yang memiliki nilai tutupan yang sama yaitu $0,3 \%$. Jenis yang paling banyak ditemukan setelah $\mathrm{CM}$ adalah $\mathrm{CF}$ yang memiliki nilai tutupan sebesar 7,6\%. Mengapa $\mathrm{CM}$ mendominasi perairan di stasiun BTMC05, hal ini diduga karena bentuk pertumbuhan CM tahan dengan arus yang kuat dan didukung dengan pernyataan Luthfi et al. (2018) [7] yaitu karang dengan bentuk pertumbuhan masif memiliki ketahanan terhadap arus, gelombang, sedimentasi yang tinggi serta kenaikan suhu. Genus yang mendominasi 
pada stasiun BTMC05 ini adalah Porites sp., Pachyseris sp.,dan Fungia sp.

\section{BTMC06 (Stasiun 6)}

Berdasarkan gambar 3f, CE mendominasi perairan pada stasiun BTMC06 dengan nilai tutupan sebesar $15,80 \%$, sedangkan nilai tutupan terendah terdapat pada ACT dengan nilai $0,33 \%$. Jenis yang paling banyak ditemukan setelah $\mathrm{CE}$ adalah $\mathrm{CM}$ yang memiliki nilai tutupan sebesar $11,60 \%$. CMR dan CS memiliki nilai tutupan yang hampir sama yaitu masing - masing 4,20\% dan
4,47\%. Mengapa CE mendominasi perairan di stasiun BTMC06, hal ini diduga karena bentuk pertumbuhan $\mathrm{CE}$ dapat tumbuh dengan baik di habitat yang cukup dalam dibanding jenis lainnya dan didukung dengan pernyataan Harahap (2004) [8], yaitu tekanan yang diterima oleh biota di kolom perairan akan semakin besar jika perairan semakin dalam. Sehingga CE dengan bentuknya yang mengerak atau merayap mengikuti bentuk substrat dapat tumbuh dengan baik. Genus yang mendominasi pada stasiun BTMC06 ini adalah Pachyseris sp., Porites sp. dan Merulina sp.

Tabel 3. Persentase tutupan kategori bentik

\begin{tabular}{lrrrrrr}
\hline \multirow{2}{*}{ Kategori Bentik } & \multicolumn{7}{c}{ Lokasi } \\
\cline { 2 - 7 } & \multicolumn{2}{c}{ Pulau Abang } & \multicolumn{5}{c}{ Pulau Abang Besar } \\
\cline { 2 - 7 } & BTMC01 & BTMC02 & BTMC03 & BTMC04 & BTMC05 & BTMC06 \\
\hline Tutupan Karang (\%) & 51.33 & 32.67 & 41.00 & 39.07 & 33.80 & 40.33 \\
Recent Dead Coral & 0.47 & 1.13 & 0.93 & 0.60 & 0.27 & 0.33 \\
(DC) & & & & & & \\
Dead Coral With & 37.60 & 59.93 & 33.67 & 40.60 & 62.53 & 51.73 \\
Algae (DCA) & 0.00 & 0.07 & 0.07 & 0.00 & 0.00 & 0.00 \\
Soft Coral (SC) & 1.60 & 3.07 & 8.73 & 4.20 & 0.47 & 4.80 \\
Sponge (SP) & 0.67 & 0.20 & 0.47 & 0.07 & 0.07 & 1.67 \\
Fleshy Seaweed (FS) & 4.60 & 1.47 & 3.07 & 2.53 & 1.00 & 1.07 \\
Other Biota (OT) & 0.07 & 0.87 & 2.87 & 2.73 & 0.00 & 0.07 \\
Rubble (R) & 3.47 & 0.07 & 6.53 & 6.27 & 0.00 & 0.00 \\
Sand (S) & 0.20 & 0.53 & 1.40 & 3.80 & 1.87 & 0.00 \\
Silt (Si) & 0.00 & 0.00 & 1.27 & 0.13 & 0.00 & 0.00 \\
Rock (RK) & Baik & Rusak & Rusak & Rusak & Rusak & Rusak \\
\hline Kondisi Terumbu & & & & & & \\
Karang & & & & & & \\
\hline
\end{tabular}




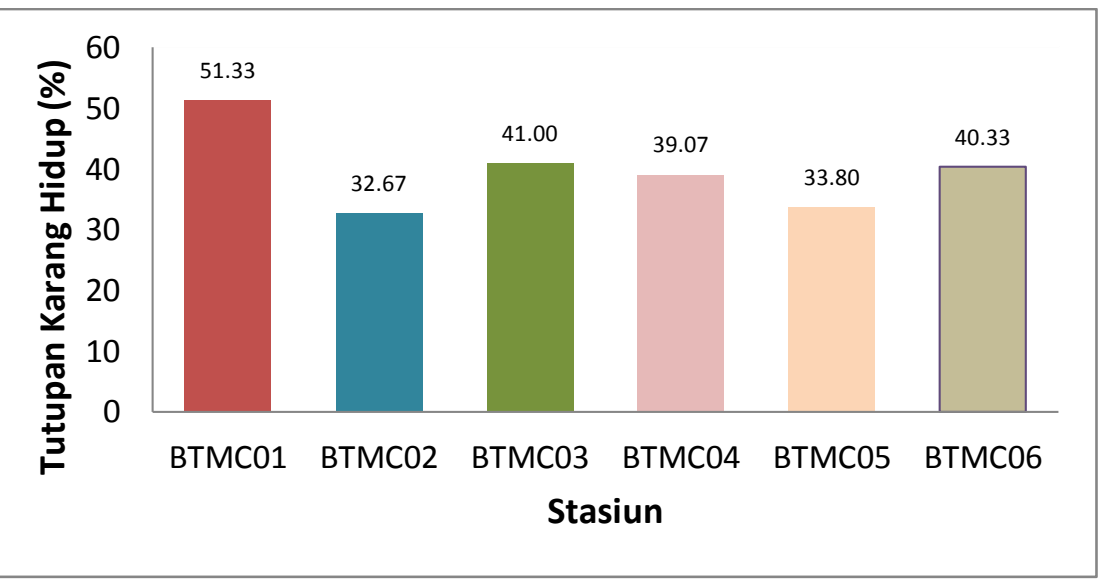

Gambar 2. Tutupan karang hidup masing - masing stasiun



(a)

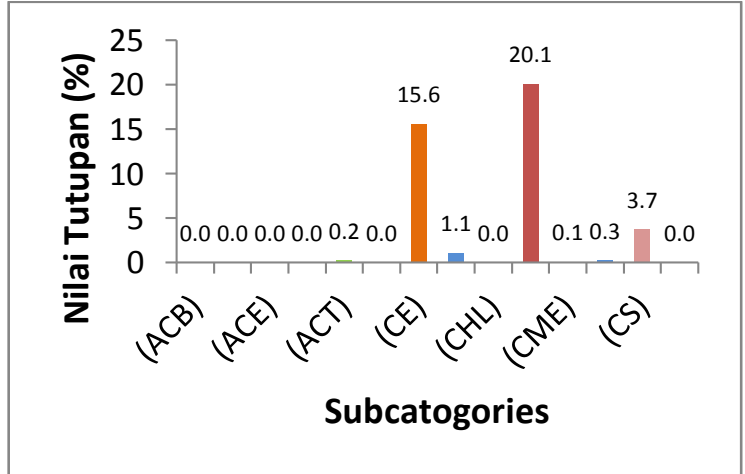

(c)

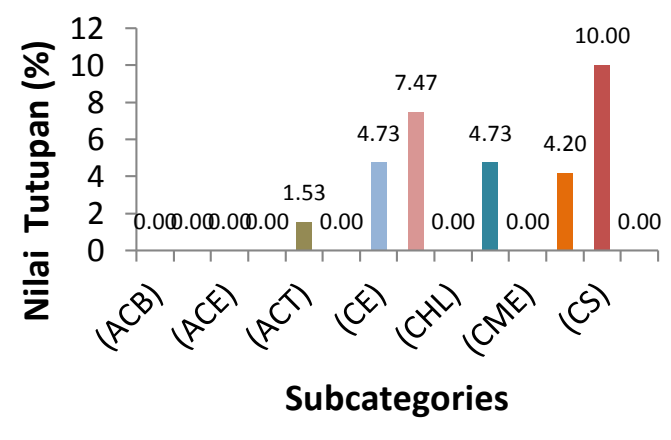

(b)



(d) 
Ramadhani, et al. / Journal of Fisheries and Marine Research Vol.3 No.3 (2019) 337-343

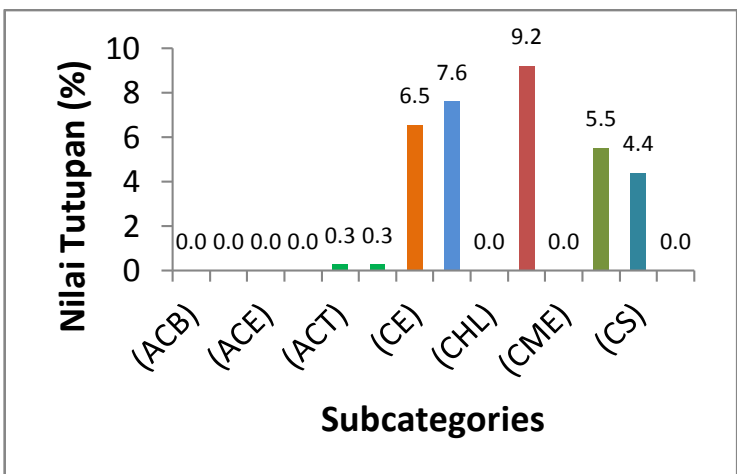

(e)

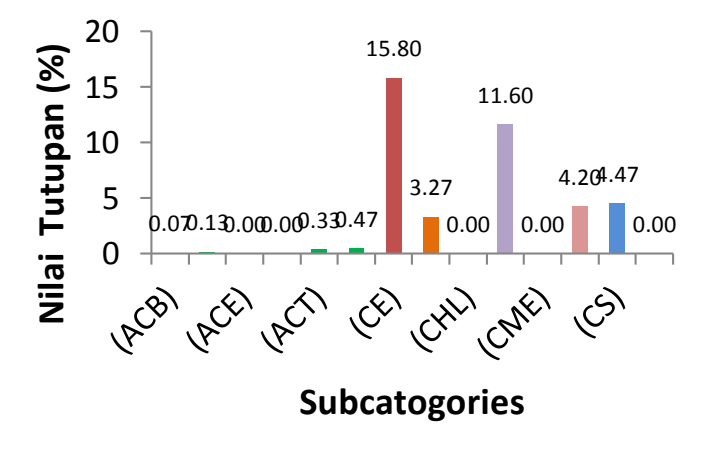

(f)

Gambar 3. Tutupan karang untuk bentuk pertumbuhan: (a) BTMC01; (b) BTMC02; (c) BTMC03; (d) BTMC04; (e) BTMC05; (f) BTMC06

Ket. ACB: Acropora Branching; ACD: Acropora Encrusting; ACE: Acropora Encrusting; ACS: Acropora Submassive; ACT: Acropora Tabulate; CB: Coral Branching; CE: Coral Encrusting; CF: Coral Foliose; CHL: Coral Heliopora; CM: Coral Massive; CME: Coral Millepora; CMR: Coral Mushroom; CS: Coral Submassive; CTU: Coral Tubipora.

\section{KESIMPULAN}

Tutupan karang tertinggi sekaligus satusatunya stasiun yang memiliki kategori kondisi terumbu karang yang baik berada pada stasiun 1 atau BTMC01 dengan persentase tutupan sebesar $51.33 \%$. Sedangkan stasiun yang memiliki persentase tutupan karang terendah yaitu dengan nilai tutupan $32.67 \%$ dengan kategori kondisi terumbu karang rusak berada pada stasiun 2 atau BTMC02. Jadi, kondisi terumbu karang di sekitar perairan Pulau Batam tergolong rusak. Baik atau buruknya tutupan karang pada suatu wilayah sangat dipengaruhi oleh kegiatan antropogenik.

\section{UCAPAN TERIMA KASIH}

Terimakasih penulis ucapkan kepada seluruh pihak yang telah membantu penulisan jurnal serta pembimbing lapang dan dosen pembimbing yang telah memberikan masukan serta membagikan ilmu yang bermanfaat.

\section{DAFTAR PUSTAKA}

[1] Giyanto, M. A.E.W, A. M, and S. R.M, Panduan monitoring kesehatan terumbu karang: Terumbu Karang, Ikan Karang,
Megabenthos, dan Penulisan Laporan. COREMAP CTI LIPI, 2014.

[2] LIPI, Monitoring Kesehatan Terumbu Karang dan Ekosistem Terkait Lainnya, Kabupaten Sikka. Jakarta: COREMAPCTI. 2015

[3] Y. V. Jaya, Andri, and I. Karlina, "Persentase Tutupan Karang Hidup di Pulau Abang Batam Provinsi Kepulauan Riau. Jurnal Ilmu Kelautan," Univ. Marit. Raja Ali Haji, vol. 2, no. 1, pp. 19, Jan. 2017.

[4] R. S. Utama and Agus Budiyanto, "Kondisi dan Keanekagaragaman Karang Batu di Perairan Sabang," Oseanologi Dan Limnol. Indones., vol. 2(1), pp. 69-82, 2017.

[5] K. E. Kohler and S. M. Gill, "Coral Point Count with Excel extensions (CPCe): A Visual Basic program for the determination of coral and substrate coverage using random point count methodology," Comput. Geosci., vol. 32, no. 9, pp. 1259-1269, Nov. 2006.

[6] Sukarno, "Mengenal Ekosistem Terumbu Karang," Pustlitbang 
Oceanogr. LIPI, vol. 1, no. 1, pp. 1-17, Jul. 1993.

[7] O. M. Luthfi, M. A. Asadi, and T. Agustiadi, "Coral Reef in Center of Coral Biodiversity (Coral Triangle): The Pulau Lirang, Southwest Moluccas (MBD)," Disaster Adv., vol. 11, p. 8, Sep. 2018.

[8] A. K. Harahap, "Kondisi Ekosistem Terumbu Karang di Perairan Sekitar Pulau Batam, Riau," Riau: Institut Pertanian Bogor, pp. 1-40, 2004. 